\title{
A one-way, valved, atrial septal patch in the management of postoperative right heart failure
}

\author{
An animal study
}

\begin{abstract}
Patients who undergo surgical repair of congenital heart defects that are characterized by hypoplastic right ventricle or pulmonary hypertension are at high risk for the development of postoperative right heart failure. To minimize this risk, a new one-way, valved, atrial septal patch was developed that serves as an artificial one-way foramen ovale. The feasibility of this device was tested in five dogs in which reversible right heart failure had been induced. Use of the one-way valved patch significantly improved right ventricular performance and reduced right ventricular hydrostatic pressures. The interatrial pressure gradient was reduced from $10 \pm 3.5 \mathrm{~mm} \mathrm{Hg}$ during right heart failure to $4.4 \pm 1.4 \mathrm{~mm}$ Hg. When the device was opened, cardiac output increased significantly. This hemodynamic improvement was achieved at the expense of systemic arterial desaturation, which was, however, well tolerated. When the state of right heart failure was reversed, the one-way valved patch spontaneously closed, allowing no interarterial shunting. The results of this experimental trial suggest that this device can play a useful role in selected patients in whom postoperative right heart failure can be anticipated after surgical repair of certain congenital heart defects. (J THORAC CardiovasC Surg 1994;108:134-9)
\end{abstract}

N. Ad, MD, J. Barak, MD, ${ }^{a}$ E. Birk, MD, S. Diamant, MD, ${ }^{a}$ and B. A. Vidne, MD, Petach Tikva and Tel-Aviv, Israel

$P$ atients who undergo an operation for the correction of congenital heart defects that are characterized by hypoplastic right ventricle (RV) or pulmonary hypertension are at a high risk for the development of right heart failure (RHF) because of decreased compliance of the RV. ${ }^{1-3}$ The conventional treatment for RHF usually improves the patient's hemodynamic status, but there are some cases in which this is not sufficient. ${ }^{4-7}$

Patients with patent foramen ovale may be less prone to the development of RHF than those without a patent foramen ovale. ${ }^{8}$ In such patients, right-to-left atrial shunting may serve to unload the $R V .^{9}$ It has been reported that the artificial creation of an atrial septal

From the Departments of Cardiothoracic Surgery, Beilinson and TelAviv $^{\mathrm{a}}$ Medical Centers, and the Sackler Faculty of Medicine, TelAviv University, Israel.

Received for publication Feb. 18, 1993.

Accepted for publication Nov. 2, 1993.

Address for reprints: Prof. B. A. Vidne, Head, Cardiothoracic Surgery Department, Beilinson Medical Center, Petach Tikva, Israel.

Copyright $\odot 1994$ by Mosby-Year Book, Inc.

$0022-5223 / 94 \$ 3.00+0 \quad \mathbf{1 2} / \mathbf{1} / \mathbf{5 2 9 8 0}$ defect in patients with RHF dramatically improved their hemodynamic state, but at the expense of desaturation of the systemic arterial blood. ${ }^{9-12}$ The major disadvantage of this procedure, however, is that the iatrogenic damage to the interatrial septum must be corrected by a subsequent invasive procedure.

The need for this further procedure can be obviated by the use of a one-way, valved, atrial septal patch. The oneway valved patch serves as a patent foramen ovale and provides a right-to-left shunt at the atrial level, but prevents any left-to-right shunt. The feasibility and effectiveness of this new technique was studied in animals. This paper describes the new technique.

\section{Materials and methods}

Five mongrel dogs weighing 20 to $25 \mathrm{~kg}$ were anesthetized, intubated, and the lungs ventilated. All animals received humane care in compliance with the "Principles of Laboratory Animal Care" (NIH Publication No. 86-23, revised 1985).

The new device (Fig. 1) is fashioned from two layers of woven Dacron fabric. A central circular opening, $0.5 \mathrm{~cm}$ in diameter, ${ }^{13,14}$ is created in one of the layers. This opening is then covered by a second, smaller Dacron fabric layer, which is sutured to the first along one side only, creating the simple mechanism of a one-way valve. Two side stitches (Fig. 1, second panel) are 

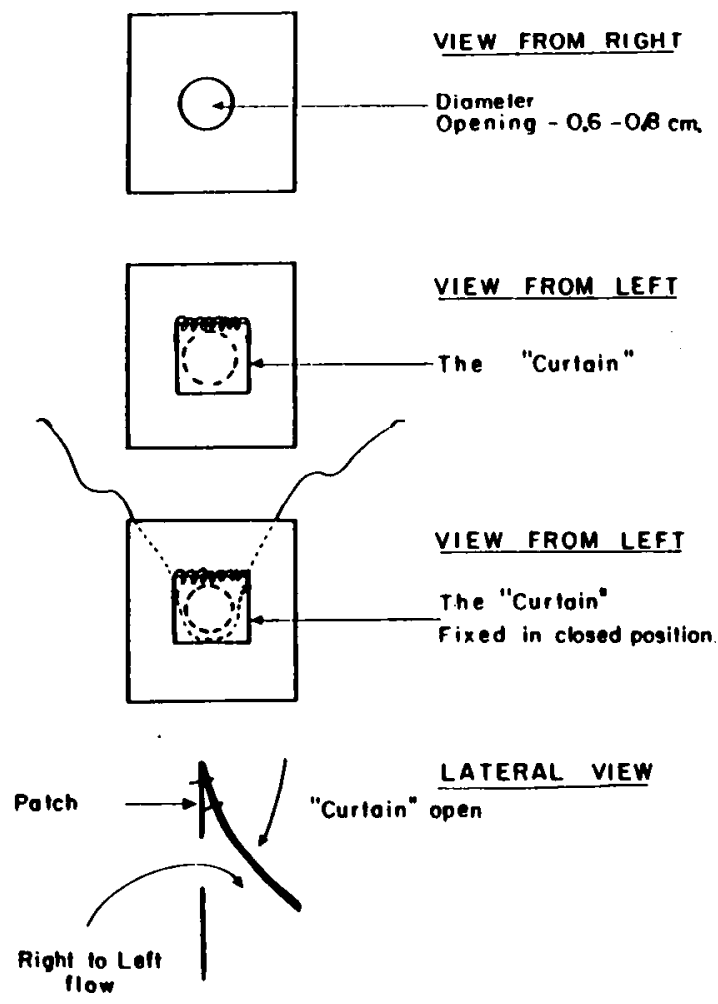

Fig. 1. Device illustrated is composed of two layers of woven Dacron fabric: first layer (top panel) with $0.5 \mathrm{~cm}$ circular opening to which second smaller layer is sutured along one side only (second panel). U suture, which maintains device in locked position, is seen in third panel. Lateral view of opened device is seen at bottom.

inserted and are important for maintaining the "curtain" in the correct position for closure. The patch used in the animal experiment contained a $U$ suture locking mechanism (Fig. 1, third panel). It was implanted in the locked position and subsequently unlocked when required by withdrawing the $U$ suture (Fig. 1, third panel). The "curtain" of the device was opened toward the roof of the atrium (Fig. 2).

Thoracotomy was done through a midsternal incision. The heart was cannulated in the usual manner and prepared for cardiopulmonary bypass. Cardiac arrest was induced by a cold $\left(3^{\circ} \mathrm{C}\right)$ crystalloid cardioplegic solution (modified St. Louis). The entire body temperature was reduced to $28^{\circ} \mathrm{C}$.

Through the right atrium a round opening, $2 \mathrm{~cm}$ in diameter, was made in the interatrial septum. The one-way, valved, atrial septal patch device was implanted in its locked position. Catheters were placed in the right atrium, left atrium, RV, and ascending aorta.

An isolated RHF model was induced by a combination of a severe reversible increase in RV afterload and mild tricuspid insufficiency. Reversible increase in RV afterload was achieved by inflating a balloon catheter placed in the distal main pulmonary artery. Tricuspid insufficiency was caused by mechanically dilating the tricuspid anulus with Tubbs dilators. The pericardium was left open during the entire experiment. $^{15}$

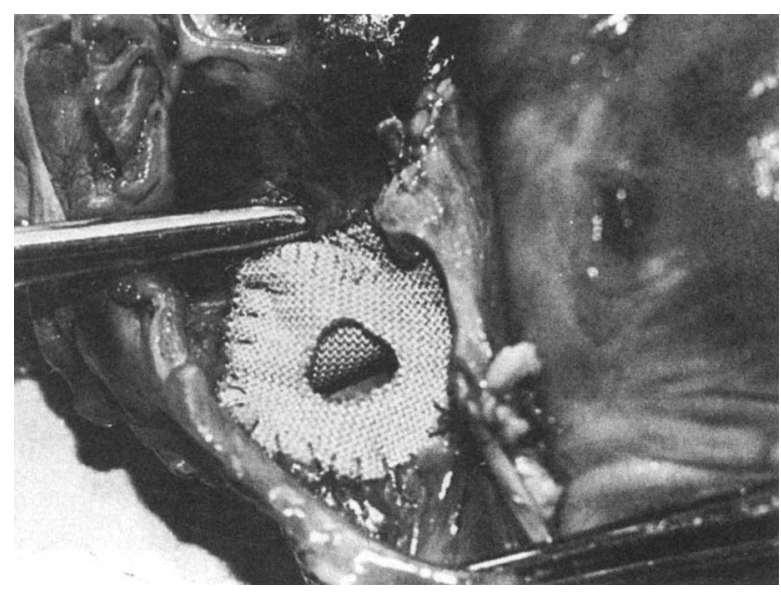

Fig. 2. One-way valve partially opened. View from opened right atrium in dog No. 5 .

(1)

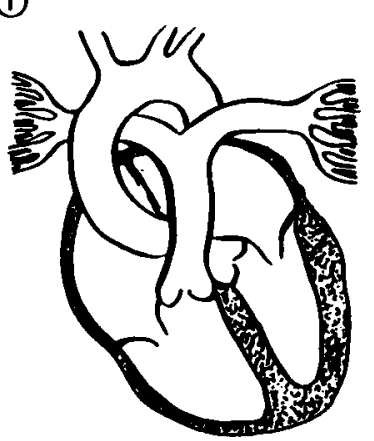

(2)

(3)

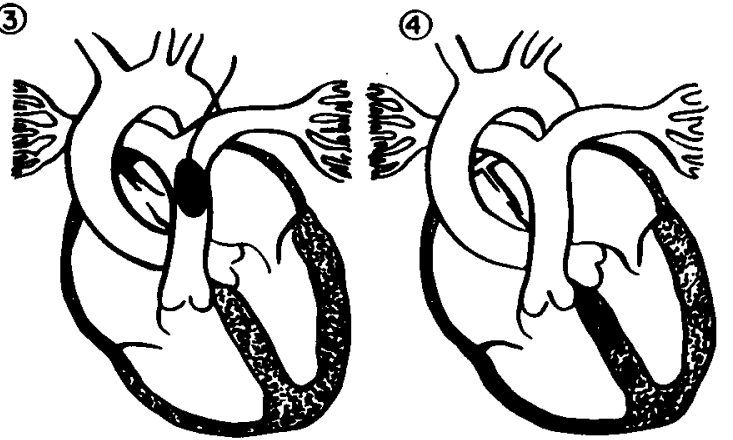

Fig. 3. Phases of experiment: phase 1 , baseline phase, $30 \mathrm{~min}$ utes after stopping cardiopulmonary bypass; phase 2 , RHF phase with maximal afterload to RV; phase 3 , opening of device allowing right atrial-to-left atrial shunting; phase 4 , reversal of RHF by deflating balloon.

The following parameters were recorded and calculated: hydrostatic pressure and oxygen saturation in the right atrium, left atrium, aorta, and RV. Systemic and pulmonary blood flows were calculated by the Fick method. ${ }^{16}$ The changes in heart 


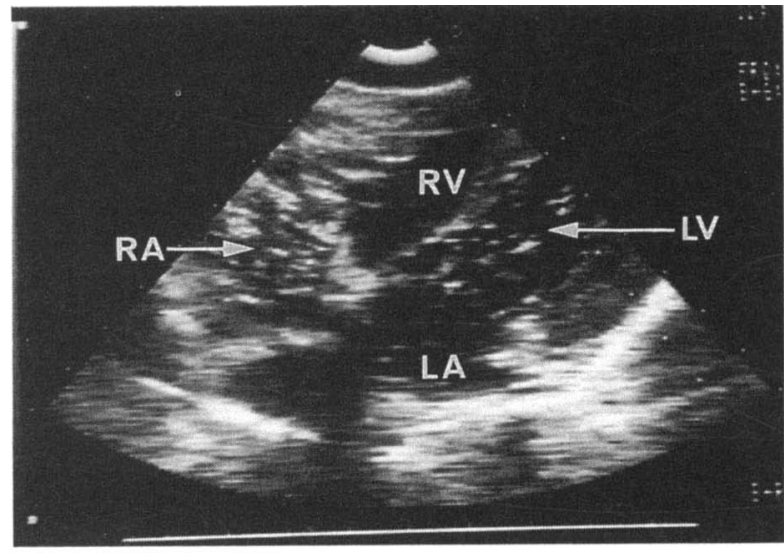

Fig. 4. Right-to-left interatrial shunt was demonstrated by injecting aerated saline containing microbubbles to systemic venous system. $L A$, Left atrium; $L V$, left ventricle; $R A$, right atrium; $R V$, right ventricle.

geometry were followed and documented by intraoperative echocardiography. The presence and direction of the interatrial shunt was further demonstrated by contrast echocardiography with the use of aerated saline containing microbubbles.

Measurements were taken during four different experimental phases (Fig. 3):

Phase 1: Measurements were taken 30 minutes after cessation of cardiopulmonary bypass (recovery period), with the one-way valved patch device in its locked position.

Phase 2: Reversible RHF was induced by gradual inflation of the balloon in the distal main pulmonary artery.

Phase 3: The one-way valved patch device was unlocked, permitting a right-to-left atrial shunt.

Phase 4: The high pulmonary artery resistance was reversed by deflating the pulmonary artery balloon. The spontaneous closure of the shunt was tested during this phase.

Data analysis. The values for each parameter are reported as the mean plus or minus the standard deviation. The changes in the oxygen saturation in the left atrium were normalized for the saturation value at the baseline state (left atrial saturation at any given phase/left atrial saturation at phase 1 ). The ratio between the pulmonic flow and the systemic flow was calculated. The statistical analysis was made with the paired Student's $t$ test. Differences were considered statistically significant at $p$ values less than 0.05 .

\section{Results}

Atrial and ventricular pressure. Table I shows the influence of the one-way, valved, atrial septal patch device on the right and left atrial pressures, RV systolic pressure, RV/LV (left ventricular) systolic pressure ratio, and the right-to-left shunt through the device during the different experimental phases. These results reflect that a state of RHF was induced in phase 2 . The opening of the device

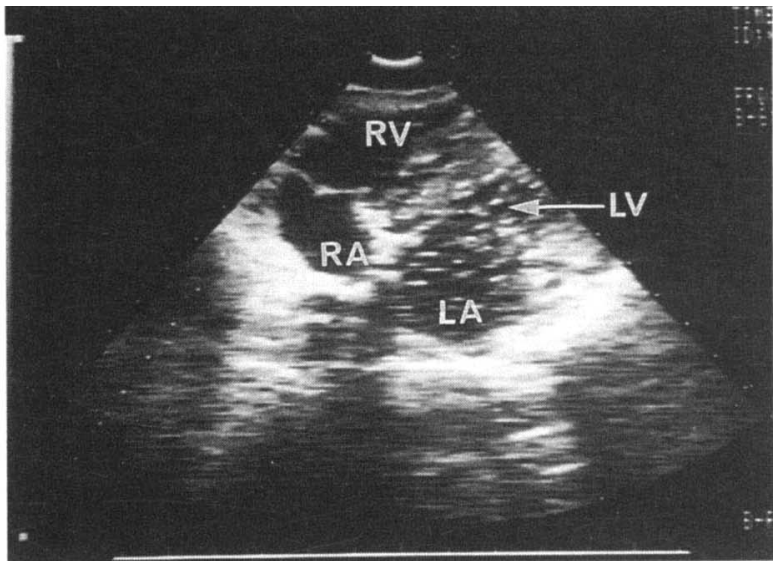

Fig. 5. No left-to-right interatrial shunt was found in phase 4 when aerated saline containing microbubbles was injected to left atrium. $L A$, Left atrium; $L V$, left ventricle; $R A$, right atrium; $R V$, right ventricle.

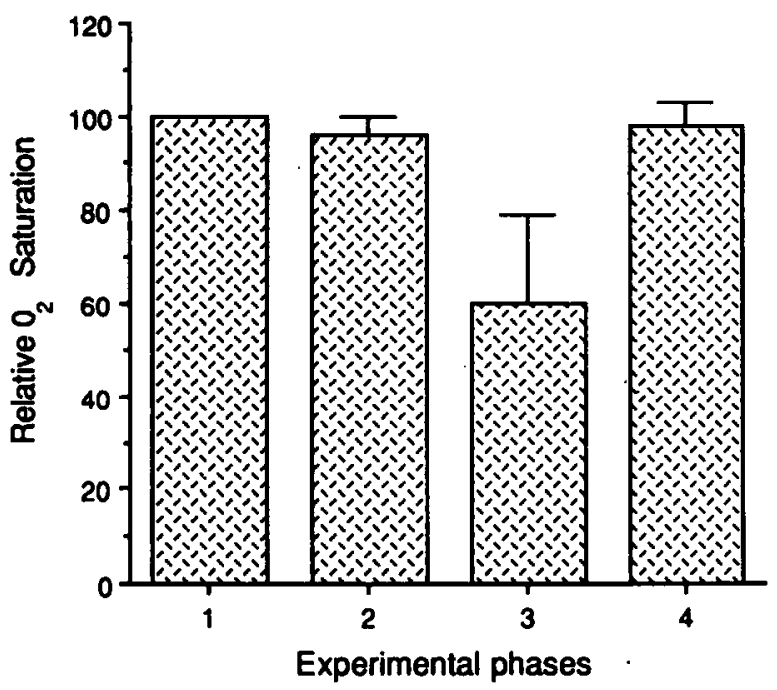

Fig. 6. Bar graphs of normalized left atrial oxygen saturation during experimental phases. Values given are ratio between left atrial saturation at any given phase of experiment and saturation at phase 1 . In phase 2 there is insignificant drop in left atrial oxygen saturation to $96 \% \pm 4 \%(p>0.05)$. In phase 3 there is steep drop to $60 \% \pm 18 \%(p<0.05)$ caused by right-to-left atrial shunting. In phase 4 left atrial oxygen saturation returned to baseline levels of $98 \% \pm 1.5 \%(p>0.05$, when compared with phase 1).

in phase 3 led to an immediate improvement of this state. In phase 4 , there was a clear tendency for all parameters to return to baseline values.

Right-to-left shunt. Contrast echocardiography dem- 


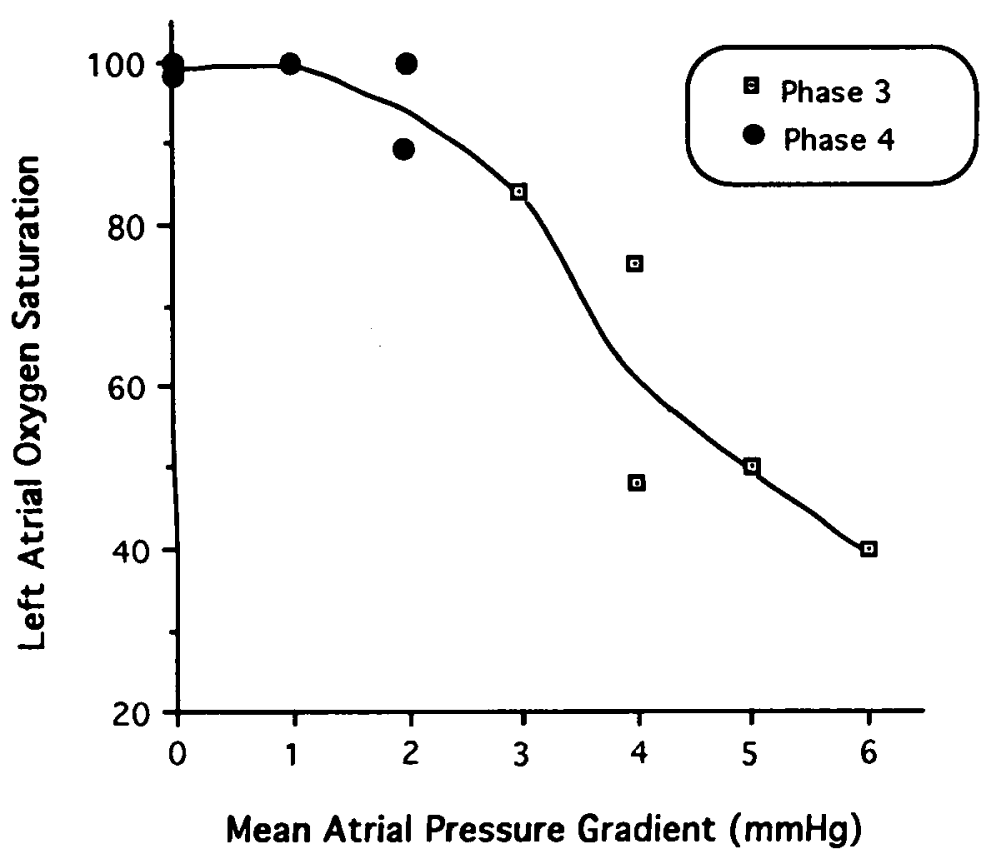

Fig. 7. Estimated opening pressure gradient of device. This graph shows correlation between right atrial-to-left atrial mean pressure gradient and left atrial oxygen saturation. Biphasic character of graph leads us to assume that opening gradient of device lies between 2 and $4 \mathrm{~mm} \mathrm{Hg}$.

Table I. Pressure in the cardiac chambers in millimeters of mercury

\begin{tabular}{cccccc}
\hline & $R A$ & $L A$ & $\begin{array}{c}R A-L A \\
\text { gradient }\end{array}$ & $\begin{array}{c}R V / L V \\
\text { ratio }\end{array}$ \\
\hline Phase 1 & $6.0 \pm 1.9^{*}$ & $3.6 \pm 1.5^{*}$ & $2.4 \pm 0.9^{*}$ & $23.6 \pm 7.5$ & $0.24 \pm 0.08$ \\
Phase 2 & $11.2 \pm 2.5$ & $1.2 \pm 0.5$ & $10.0 \pm 3.6$ & $49.6 \pm 9.5$ & $0.83 \pm 0.12$ \\
& $(p<0.05)$ & $(p<0.05)$ & $(p<0.05)$ & $(p<0.05)$ & $(p<0.05)$ \\
Phase 3 & $7.1 \pm 1.5$ & $3.2 \pm 1.6$ & $4.4 \pm 1.1$ & $44.2 \pm 8.2 \dagger$ & $0.6 \pm 0.17$ \\
& $(p<0.05)$ & $(p<0.05)$ & $(p<0.05)$ & & $(p<0.05)$ \\
Phase 4 & $4.0 \pm 1.9$ & $3.0 \pm 1.2 \dagger$ & $1.0 \pm 0.7$ & $34.6 \pm 5.7$ & $0.44 \pm 0.14 \dagger$ \\
& $(p<0.05)$ & & $(p<0.05)$ & $(p<0.05)$ & \\
\hline
\end{tabular}

All atrial pressures are expressed as mean pressure; ventricular pressures and ratios are peak systolic pressures. $R A$, Right atrium; $L A$, left atrium; $R V$, right ventricle; $L V$, left ventricle.

* Nonsignificant when compared with phase 4 value.

†Nonsignificant.

onstrated the flow through the opened one-way valved patch in phase 3 with a significant right atrial-to-left atrial shunt (Fig. 4). No left atrial-to-right atrial shunt was demonstrated during phase 4 (Fig. 5). Fig. 6 shows the clear reduction of left atrial oxygen saturation to $60 \% \pm 18 \%$ of baseline. During phase 3 , as a result of right-to-left shunt in phase 4 , this value returned to baseline levels.

Flow measurements. With the use of the Fick meth- od $^{16}$ it was shown that in phase 2 the pulmonic flow/systemic flow ratio was $0.84: 1$ and in phase 3 it was $0.51: 1$. The systemic flow was elevated from 3.2 $\mathrm{L} / \mathrm{min}$ in phase 2 to $5.83 \mathrm{~L} / \mathrm{min}$ in phase $3(82.3 \%$ elevation).

Geometric changes. Echocardiography showed a significant dilation of the RV and a pushed-back LV during phase 2. The reversal of this state was observed during phase 3. 


\section{Discussion}

The animal studies demonstrated the feasibility of the one-way, valved, atrial septal patch and its benefits in the RHF state. Right-to-left shunt at the atrial level was demonstrated by echocardiography (Fig. 4) and by the steep drop in blood oxygen saturation in the left atrium (Fig. 6). Leaving an opened atrial septal defect or patent foramen ovale is a well-known surgical option when patients who are at high risk for postoperative RHF are operated on. ${ }^{17-18}$ Using the one-way valved patch device to retain this option for interatrial shunt if required provides a safety valve for a temporarily failing $R V$. The question remains whether interatrial right-to-left shunt does improve the hemodynamic state.

In phase 2, there was an elevation of the RV pressure and a reduction of $\mathrm{LV}$ pressure, which led to a low cardiac output state. Echocardiography demonstrated a shift of the interventricular septum to the left and dilation of the RV cavity.

Opening the device reduced the RV pressure to $44 \mathrm{~mm}$ $\mathrm{Hg}$, which was statistically significant. However, there was an improvement in the global function of the heart, as was demonstrated by echocardiography. The shunt also improved the LV preload, which in turn improved cardiac output as shown by flow measurements. RV/LV pressure ratio was reduced significantly as a result of the shunt (Table I). Right atrial pressure fell significantly during phase 3 , which resulted in a reduction of $\mathrm{RV}$ enddiastolic pressure. The improvement in cardiac output and the reduction in $\mathrm{RV}$ end-diastolic pressure improved the RV coronary blood flow, which in turn improved RV function.

The reduction in arterial oxygen saturation could be life-threatening. ${ }^{19-20}$ However, our data showed that when oxygen desaturation of $37.5 \%$ occurred, cardiac output doubled, so it can be assumed that the oxygen transport improved. ${ }^{21}$ Theoretically the device should be opened whenever there is a gradient between the right atrium and the left atrium. However, in phase 4, despite a gradient of more than $1 \mathrm{~mm} \mathrm{Hg}$, the device was closed, which showed that it was resisting opening. When does the device open? Fig. 7 shows the relationship between the left atrial oxygen saturation and the right atrial-left atrial gradient. The biphasic character of the graph indicates that the device was opened in a gradient between 2 and $4 \mathrm{~mm} \mathrm{Hg}$.

This resistance to opening of about $3 \mathrm{~mm} \mathrm{Hg}$ can be controlled by clamping the diameter of the opening of the device or altering the site of the side stitches. The fact that the resistance can be controlled enables us to deal with critical malformations inasmuch as on the one hand antegrade flow through the $\mathrm{RV}$ is maintained and on the other hand the option of venting the RV is retained. The one-way characteristic of the device was proved by echocardiography (Fig. 5) and by oxygen saturation measurements that clearly showed that in phase 4 there was no shunt.

This information forms the base for a prospective clinical trial, the results of which will be submitted for publication in a separate article.

\section{R E F ER E N C ES}

1. Kirklin JW, Blackstone EH, Shimasaki Y, et al. Survival, functional status, and reoperation after repair of tetralogy of Fallot with pulmonary atresia. J THORAC CARDIOVASC SURG 1988;96:102-16.

2. Gonzales AC, Brandon TA, Fortune KL, et al. Acute right ventricular failure is caused by inadequate right ventricular hypothermia. J THORAC CARDIOVASC SURG 1985; 89:386-99.

3. Henonen J, Salmenpera M, Takkunen O. Increased pulmonary artery diastolic-pulmonary wedge pressure gradient after cardiopulmonary bypass. Can Anaesth Soc J 1985;32:165-70.

4. Spence PA, Weisel RD, Salerno TA. Right ventricular failure: pathophysiology and treatment. Surg Clin North Am 1985;65:689-97.

5. Cohn JN, Guiha NH, Broder MI, Limas CJ. Right ventricular infarct: clinical and hemodynamic features. Am J Cardiol 1974;33:209-14.

6. D'Ambra MN, Laraia DJ, Philbin DM, Watkins WD, Hilgenberg AD, Buckley MJ. Prostaglandin $E_{1}$ : a new therapy for refractory right heart failure and pulmonary hypertension after mitral valve replacement. J THORAC CARDIOVASC SURG 1985;89:567-72.

7. Gains WE, Pierce WS, Prophet GA, Holtzman K. Pulmonary circulatory support. J THORAC CARDIOvaSC SURG 1984;88:958-64.

8. Hagen PT, Scholz DG, Edwards WA. Incidence and size of patent foramen ovale during the first 10 decades of life: an autopsy study of 965 normal hearts. Mayo Clin Proc 1984;59:17-20.

9. Swanson MJ, Fobaz AG, Jung JY. Successful treatment of right ventricular failure with atrial septostomy. Chest 1987;92:950-2.

10. Caralps JM, Padro JM, Camara ML, Aris A, Bonin O. Creation of an atrial septal defect for acute postperfusion right ventricular failure. Ann Thorac Surg 1987;43:435-6.

11. Nihill MR, O'Laughlin MP, Mullins LE. Blade and balloon atrial septostomy is effective palliation for terminal cor pulmonale. Am J Cardiol 1987;60:683-7.

12. Laks H, Billingsley AM. Advances in the treatment of pulmonary atresia with intact ventricular septum. Cardiol Dis 1987;7:387-98.

13. Alexander JA, Rembert WC, Sealy WC, Greenfield JC. 
Shunt dynamics in experimental atrial septal defect in dogs. J Appl Physiol 1975;39:281-6.

14. Douglas JE, Rembert WC, Sealy WC, Greenfield JC. Factors affecting shunting in experimental atrial septal defect in dogs. Circ Res 1969;24:493-505.

15. Vlahakes GJ, Turley K, Hoffman JIE. The pathophysiology of failure in acute right ventricular hypertension: hemodynamic and biochemical correlations. Circulation 1983;63:87-95.

16. Braunwald E. Heart disease. New York: WB Saunders, 1988:189-90.

17. de Leval MR, Bull C, Stark J, Anderson RH, Taylor JFN, Macartney FJ. Pulmonary atresia and intact ventricular septum: surgical management based on a revised classification. Circulation 1982;66:272-80.
18. Engle MA, Taussig HB. Valvular pulmonic stenosis with intact ventricular septum and patent foramen ovale. Circulation 1950;2:481-93.

19. Karagoz HY, Tasdemir O, Yakut C, Bayazit K. Atrial septal defect for right ventricular failure. Ann Thorac Surg 1988;45:350-1.

20. Krueger SK, Lappe DL. Right to left shunt through patent foramen ovale complicating right ventricular infarction. Chest 1988;94:1100-1.

21. Laks H. The partial Fontan procedure: a new concept and its clinical application [Editorial]. Circulation 1990; 82:1866-7.

\section{Bound volumes available to subscribers}

Bound volumes of THE JOURNAL OF THORACIC AND CARDIOvASCULAR SURGERY are available to subscribers (only) for the 1994 issues from the Publisher, at a cost of $\$ 82.50$ for domestic, $\$ 106.28$ for Canadian, and $\$ 100.50$ for international subscribers for Vol. 107 (January-June) and Vol. 108 (July-December). Shipping charges are included. Each bound volume contains a subject and author index and all advertising is removed. Copies are shipped within 60 days after publication of the last issue of the volume. The binding is durable buckram with the JOURNAL name, volume number, and year stamped in gold on the spine. Payment must accompany all orders. Contact Mosby-Year Book, Inc., Subscription Services, 11830 Westline Industrial Drive, St. Louis, Missouri 63146-3318, USA; phone 1 (800) 4534351 or (314) $453-4351$.

Subscriptions must be in force to qualify. Bound volumes are not available in place of a regular JourNaL subscription. 